http://jmscr.igmpublication.org/home/

ISSN (e)-2347-176x ISSN (p) 2455-0450

crossref DOI: https://dx.doi.org/10.18535/jmscr/v7i9.01

Journal Of Medical Science And Clinical Research

IGM Publication

An Official Publication of IGM Publication

\title{
Prevalence of undiscovered fatigue among Indian corporate workers and the factors associated with it: results from a cross-sectional mailed questionnaire-based survey
}

\author{
Authors \\ Dr Suman Biswas ${ }^{1}$, Dr Shuvankar Mukherjee ${ }^{2 *}$, Dr Nabanita Bhattacharyya ${ }^{3}$, \\ Dr Biswanath Sharma Sarkar ${ }^{4}$ \\ ${ }^{1}$ Independent Researcher, Dept. of Community Medicine, Calcutta National Medical College, Kolkata \\ ${ }^{2}$ Assistant Professor, Dept. of Community Medicine, Calcutta National Medical College, Kolkata \\ ${ }^{3}$ Professor \& Head of the dept. of Community Medicine, Calcutta National Medical College, Kolkata \\ ${ }^{4}$ Associate Professor, Dept. of General Medicine, Diamond Harbour Government Medical College \& \\ Hospital, West Bengal \\ *Corresponding Author
}

Dr Shuvankar Mukherjee

Assistant Professor, Dept. of Community Medicine, Calcutta National Medical College, Kolkata, India

\begin{abstract}
Introduction: Fatigue and its attributes among corporate sector workers are not well studied in India. The present study was conducted with the objective to find out the level of fatigue among corporate workers across four major cities in India and to find out the factors associated with it.

Methods: Both Male and Female workers between age 24 to 40 years old working in the corporate sectors in 4 big cities in India were asked to fill up an anonymous 20-item questionnaire over the internet. Data were analyzed with SPSS version 20.0.

Results: About $80 \%$ of the respondents had moderate to severe fatigue score while $20 \%$ had mild fatigue score. Univariate analysis showed that consumption of coffee 61( $p=.028)$, and tea during work 84 $(p=.042)$, and smoking cigarettes $36(p=.042)$ and recreational cannabis usage 24 ( $p=.033)$ were significantly more frequent among those with moderate to severe fatigue score. However, binary logistic regression analysis revealed that female sex, night shift of work and alcohol consumption during work were significantly higher in the population with moderate to severe fatigue in comparison to mild fatigue. Females are almost 6 times ( $p=.003, C I=1.851-18.369)$, night shift workers almost 11 times $(p=.029$, $C I=1.268-89.833)$ and those who consumed alcohol during work were 11 times more affected with moderate to severe fatigue ( $p=.045, C I=1.058-118.115$ ).
\end{abstract}

Conclusion: A large proportion of the study subjects suffered from moderate to severe fatigue which showed a significant relationship with female sex, night shift work and alcohol consumption.

Keywords: Shift Work, Fatigue, Corporate Workers, India, Prevalence of Fatigue, Mental health.

\section{Introduction}

Fatigue is just not feeling drowsy and tired. In the context of work, it is a state of mental and/or physical exhaustion which reduces a person's ability to perform effectively and moreover safely. Prolonged mental and physical work, sleep disturbance and disturbance of the internal body clock can cause fatigue. Fatigue can be due to 
factors which might be work-related, non-work related or a combination of both. It is distributed in a normal curve in the general population and 5$10 \%$ patients present with fatigue to their physicians. ${ }^{(1,2)}$ Also, fatigue can accumulate over time. It has been a part of diseases and it has been a pathology by its own. It is associated with both psychiatric and medical diseases, as well as therapies like cancer chemotherapy too. ${ }^{(3-6)}$ Fatigue is also an integral part of Chronic Fatigue Syndrome (CFS) and Major Depressive Disorders (MDD) both are associated with risk for suicidality. ${ }^{(7-9)}$ Though some studies have revealed that shift workers have more prevalence of fatigue (10-13), the fatigue level in the general workingclass population is not well studied in India. In this backdrop, the present study was conducted with the objective to find out the level of fatigue among corporate workers across four major cities in India and to find out the factors associated with it.

\section{Material and Methods}

This cross-sectional observational study was conducted in the Department of Community Medicine of Calcutta National Medical College and Hospital, Kolkata, West Bengal, India, during the period of September to November 2018. Ethical clearance was obtained from the ethics committee of this institute. A pre-designed, pretested self-administered questionnaire (Annexure 1) was used which was adopted from Brief Fatigue Inventory (BFI). ${ }^{(14)}$ This questionnaire was structured in Google Forms ${ }^{\circledR}$ for distribution over the internet as a mailed questionnaire. Eleven additional questions were added pertained to age, sex, relationship status, change in sexual behaviors, the shift of work, perceived concentration power, used addictive substances and their used methods to remain fresh and 'stay awake' during work hours. Thus, each questionnaire contained 20 self-administered questions. The questionnaire was first distributed among four key corporate workers selected purposively, in the four major cities of India and then it was distributed to the corporate workers of their respective companies through them. Each of the participants was briefed about the purpose of the study and informed consent was taken from everyone. The data were collected individually for both men and women working at Bangalore, Delhi-Gurgaon, Pune and Kolkata corporate offices purposively for the convenience of the research. Altogether $(n=) 153$ completed forms were returned. Fatigue was measured as fatigue score which was a 10 -scale measurement and it was graded as none (0), mild (1-3), moderate (4-6) and severe (7-10). ${ }^{(15)}$

Statistical analysis: Data were analyzed using SPSS (Statistical Package for Social Sciences) Version 20.0 IBM Corporation, Armonk, New York, USA. Univariate analysis was done initially using the chi-square test. In the next step, those variables showing a $p$-value of $\leq .2$ were subjected to binary logistic regression analysis. A $p$ value of $\leq .05$ was considered statistically significant.

\section{Results}

Majority of the respondents belonged to 25-29 year age group [60.8\% (93/153)]. Male and female were almost equal in number i.e. $52.9 \%$ $(81 / 153)$ and $47.1 \%(72 / 153)$ respectively (Table 1). It was observed that $79.7 \%(122 / 153)$ of the respondents had moderate to severe fatigue score while 20.35 had mild fatigue score. (Table 2). Among the study subjects $45.8 \%$ people $(70 / 153)$ consumed alcohol outside of work, $23.3 \%$ (36/153) smoked a cigarette during work and $15.7 \%$ (24/153) used cannabis, 3.9\% (6/153) used cocaine and $3 \%$ people (3/153) used heroin as recreational activities. Interestingly, almost $14 \%$ (21/153) of respondents consume alcohol (mostly beer) during working hours and $95 \%$ of them (20/21) are suffering from moderate to severe fatigue. Univariate analysis showed that colnsumption of coffee $(\mathrm{p}=.028)$, and tea during work $(p=.042)$, and smoking cigarettes $(p=.042)$ and recreational cannabis usage $(\mathrm{p}=.033)$ were significantly more frequent among those with moderate to severe fatigue score. (Table 2) 
However binary logistic regression analysis revealed that female sex, the night shift of work and alcohol consumption during work were significantly higher in the population with moderate to severe fatigue in comparison to mild fatigue. Females are almost 6 times $(\mathrm{CI}=1.851$ 18.369, $\mathrm{p}=.003)$, night shift workers almost 11 times $(\mathrm{CI}=1.268-89.833, \mathrm{p}=.029)$ and those who consumed alcohol during work were 11 times more affected with moderate to severe fatigue $(\mathrm{p}=.045, \mathrm{CI}=1.058-118.115)$. (Table 3$)$
Table 1: Age and sex-wise distribution of the study subjects $(\mathrm{n}=153)$

\begin{tabular}{|l|c|c|}
\hline Age group (years) & $\frac{\text { Male }}{9}$ & Female \\
\hline $20-24(\mathrm{n}=18)$ & 9 & 9 \\
\cline { 2 - 3 } & $50.0 \%$ & $50.0 \%$ \\
\hline \multirow{2}{*}{$25-29(\mathrm{n}=93)$} & 48 & 45 \\
\hline \multirow{2}{*}{$\geq 30(\mathrm{n}=42)$} & 24 & $48.4 \%$ \\
\cline { 2 - 3 } & $57.1 \%$ & 18 \\
\hline \multirow{2}{*}{ Total $(\mathrm{n}=153)$} & 81 & $42.9 \%$ \\
\cline { 2 - 3 } & $52.9 \%$ & $47.1 \%$ \\
\hline
\end{tabular}

Table 2: Relation between different variables and fatigue level

\begin{tabular}{|c|c|c|c|}
\hline \multirow[t]{2}{*}{$\underline{\text { Variables }}$} & \multicolumn{2}{|c|}{ Fatigue level } & \multirow[t]{2}{*}{ p value } \\
\hline & Mild & Moderate-severe & \\
\hline \multirow[t]{2}{*}{ Age } & 4 & 15 & $\mathrm{p}=.927$ \\
\hline & 27 & 107 & \\
\hline \multirow[t]{2}{*}{ Sex: } & 21 & 60 & $\mathrm{p}=.064$ \\
\hline & 10 & 62 & \\
\hline \multirow[t]{2}{*}{ Shift: } & 30 & 102 & $\mathrm{p}=.057$ \\
\hline & 1 & 20 & \\
\hline \multirow{2}{*}{ Coffee: } & 24 & 68 & $\mathrm{p}=.028$ \\
\hline & 7 & 54 & \\
\hline \multirow[t]{2}{*}{ Alcohol during work: } & 30 & 102 & $\mathrm{p}=.057$ \\
\hline & 1 & 20 & \\
\hline \multirow[t]{2}{*}{ Tea: } & 19 & 50 & $\mathrm{p}=.042$ \\
\hline & 12 & 72 & \\
\hline \multirow[t]{2}{*}{ Gym \& Meditation: } & 20 & 83 & $\mathrm{p}=.709$ \\
\hline & 11 & 39 & \\
\hline \multirow{2}{*}{ Cigarette: } & 28 & 89 & $\mathrm{p}=.042$ \\
\hline & 3 & 33 & \\
\hline \multirow{2}{*}{ Alcohol outside of work: N } & 18 & 65 & $\mathrm{p}=.633$ \\
\hline & 13 & 57 & \\
\hline \multirow[t]{2}{*}{ Cannabis Usage: } & 30 & 99 & $\mathrm{p}=.033$ \\
\hline & 1 & 23 & \\
\hline \multirow[t]{2}{*}{ Heroin: } & 31 & 119 & $\mathrm{p}=.378$ \\
\hline & 0 & 3 & \\
\hline \multirow[t]{2}{*}{ Cocaine: } & 31 & 116 & $\mathrm{p}=.208$ \\
\hline & 0 & 6 & \\
\hline \multirow{2}{*}{ Talking with other: } & 31 & 119 & $\mathrm{p}=.378$ \\
\hline & 0 & 3 & \\
\hline
\end{tabular}

Table 3: Binary logistic regression analysis showing relationship of different factors with fatigue level

\begin{tabular}{|l|c|c|c|c|}
\hline Factors & p value & Odds Ratio & \multicolumn{2}{|c|}{ 95\% C.I. } \\
\cline { 4 - 5 } & & & Lower & Upper \\
\hline Sex & .003 & 5.83 & 1.851 & 18.369 \\
\hline Work shift & .029 & 10.673 & 1.268 & 89.833 \\
\hline Coffee \& caffeinated drink & .342 & 1.705 & .567 & 5.129 \\
\hline Alcohol consumption & .045 & 11.18 & 1.058 & 118.115 \\
\hline Tea during work & .928 & .946 & .288 & 3.107 \\
\hline Gym during work & .754 & 1.196 & .390 & 3.67 \\
\hline Talking with other & .090 & .313 & .082 & 1.198 \\
\hline Cigarette smoking & .426 & 1.888 & .395 & 9.020 \\
\hline Cannabis smoking & .064 & 8.202 & .883 & 76.159 \\
\hline
\end{tabular}




\section{Discussion}

In the present study, a substantial proportion of the respondents (around 80\%) were found to be having moderate to severe fatigue. It was found that almost $14 \%$ of the respondents consumed alcohol during work and most of them [95\% (20/21)] are having moderate to severe fatigue. Though similar studies were not found to compare with the findings of the present study, Yuan et al. found that among nurses of Taiwan, night shift workers have more fatigue than day workers (Odds Ratio=2.44, $\mathrm{P}<$ 0.10). ${ }^{(10)}$ Similarly, Åkerstedt, et al. found that fatigue among shift workers are mainly due to malalignment of the circadian rhythm that might be a major reason behind the fatigue. ${ }^{(11)}$ Jansen et al. also supported that in their study. ${ }^{(12)}$ Similarly, the present study found that night shift workers are almost 11 times more fatigued in comparison to day shift workers. Besides that, the study also found that in comparison with male counterparts, female corporate workers were having significantly more associated with moderate to severe fatigue. Corporate workers with moderate to severe fatigue also found to be consuming alcohol (mainly beer) during their working hours possibly to cope up with their fatigue. Thus, the present study reveals the undiscovered fatigue among Indian corporate workers and asks for a close attention from the community of health workers and researchers. Many government authorities and researchers have already recommended strategies for several types fatigue management. ${ }^{(16,17,18)}$ Studies have also shown more errors and lesser productivity in a fatigued individual in an industry set up. (19) The population should be properly educated regarding fatigue management and they should be evaluated further for any psychiatric or medical illness. A significant proportion of the population also needs counseling regarding alcohol and other recreational substance use.

\section{Conclusion}

A large proportion of the study subjects suffered from moderate to severe fatigue which showed a significant relationship with female sex, night shift work and alcohol consumption.

The authors recommend that fatigue and its associated factors need periodic counseling at regular intervals among corporate workers and education about how to manage this in the day to day life.

\section{Limitation}

The present study has its own limitation. First, it was done for a short interval of a period of only 8 weeks and relatively small population of 153 respondents were included in the study. For the convenience of the study it was done in four major cities in India other places of were not included.

\section{References}

1. Sharpe M. ABC of psychological medicine: Fatigue. BMJ 2002: 325 (7362): 480-483.

2. Safe Work Australia. (2017). Fatigue. [online] Available at: http://safeworkaustralia.gov.au/ [Accessed 3 Dec. 2018].

3. Phillips R. A review of definitions of fatigue - And a step towards a whole definition. Transportation Research Part F: Traffic Psychology and Behaviour 2015; 29:48-56.

4. Stadje R., Dornieden K., Baum E., Becker A., Biroga T., Bösner $S$ et al. The differential diagnosis of tiredness: a systematic review. BMC Family Practice 2016; 20: 17(1): 147.

5. Griffith J, Zarrouf F. A Systematic Review of Chronic Fatigue Syndrome. The Primary Care Companion to The Journal of Clinical Psychiatry 2008; 10 (02):12028.

6. Saligan L, Olson K, Filler K, Larkin D, Cramp F, Sriram Y et al. The biology of cancer-related fatigue: a review of the literature. Supportive Care in Cancer. 2015; 23 (8):2461-78. 
7. Smith WR, Noonan C, Buchwald D. Mortality in a cohort of chronically fatigued patients. Psychological medicine. 2006; 36 (9):1301-6.

8. Roberts E, Wessely S, Chalder T, Chang CK, Hotopf M. Mortality of people with chronic fatigue syndrome: a retrospective cohort study in England and Wales from the South London and Maudsley NHS Foundation Trust Biomedical Research Centre (SLaM BRC) Clinical Record Interactive Search (CRIS) Register. The Lancet 2016 16; 387 (10028):1638-43.

9. Oquendo MA, Galfalvy H, Russo S, Ellis SP, Grunebaum MF, Burke A, Mann JJ. Prospective study of clinical predictors of suicidal acts after a major depressive episode in patients with major depressive disorder or bipolar disorder. American Journal of Psychiatry 2004; 161(8): 143341.

10. Yuan S, Chou M, Chen C, Lin Y, Chen M, Liu $\mathrm{H}$ et al. Influences of shift work on fatigue among nurses. Journal of Nursing Management. 2011; 19 (3): 339-345.

11. Åkerstedt T, Wright K. Sleep Loss and Fatigue in Shift Work and Shift Work Disorder. Sleep Medicine Clinics 2009; 4(2): 257-71.

12. Jansen N, van Amelsvoort LGPM, Kristensen T, van den Brandt PA, Kant I. Work schedules and fatigue: a prospective cohort study. Occupational and Environmental Medicine. 2003; 60 (Suppl 1): i47-i53.

13. Salve U. Relationship of duration of work exposure and feeling of subjective fatigue: A case study on jewelry manufacturing workers in India. International Journal of Environmental Health Engineering. 2017; $6(1): 1$.
14. Brief Fatigue Inventory (Index) [Internet]. Shirley Ryan Ability Lab - Formerly RIC. 2018. Available from: https://www.sralab.org/rehabilitationmeasures/brief-fatigue-inventory-index. [accessed 3 December 2018]

15. Iwase S, Kawaguchi T, Tokoro A, Yamada K, Kanai Y, Matsuda Y et al. Assessment of Cancer-Related Fatigue, Pain, and Quality of Life in Cancer Patients at Palliative Care Team Referral: A Multicenter Observational Study (JORTC PAL-09). PLOS ONE 2015; 10 (8): e0134022.

16. Yazdi Z, Sadeghniiat-Haghighi K. Fatigue management in the workplace. Industrial Psychiatry Journal 2015; 24 (1): 12.

17. Workplace Fatigue Management - HSL. (2018). Hsl.gov.uk. Retrieved 3 December 2018, from https://www.hsl.gov.uk/workplace-fatiguemanagement [accessed 3 December 2018].

18. WorkSafe [Internet]. WorkSafe Queensland 2018. Available from: https://www.worksafe.qld.gov.au/ [accessed 3 December 2018].

19. Yeow J, Ng P, Tan K, Chin T, Lim W. Effects of Stress, Repetition, Fatigue and Work Environment on Human Error in Manufacturing Industries. Journal of Applied Sciences 2014; 14 (24): 3464-71. 
(Annexure 1)

I understand it's a medical research data which will be analyzed by healthcare professionals for understanding and improving health of corporate workers. NO third party is involved. Your identity and preferences are completely safe and confidential. Data are gathered ANONYMOUSLY. Please answer honestly.

Yes No

Brief Fatigue Index (BFI) Based Questions:

1. Have you felt unusually tired or fatigued in the last week? Yes No

2. Please rate your fatigue (weariness, tiredness) by CLICKING the one number that best describes your fatigue RIGHT NOW [0-10]

3. Please rate your fatigue (weariness, tiredness) by CLICKING the number that best describes your USUAL level of fatigue during the past 24 hours [0-10]

4. Please rate your fatigue (weariness, tiredness) by CLICKING the number that best describes your WORST level of fatigue during the past 24 hours. [0-10]

5. TICK the one number that describes how, during the past 24 hours, fatigue has interfered with your GENERAL ACTIVITY OF DAY TO DAY LIFE [0-10]

6. TICK the one number that describes how, during the past 24 hours, fatigue has interfered with your MOOD [0-10]

7. TICK the one number that describes how, during the past 24 hours, fatigue has interfered with your WALKING ABILITY [0-10]

8. TICK the one number that describes how, during the past 24 hours, fatigue has interfered with your NORMAL WORK (WORK OUTSIDE AND INSIDE HOME AND DAILY CHORES.) [0-10]

9. TICK the one number that describes how, during the past 24 hours, fatigue has interfered with your RELATIONS WITH OTHER PEOPLE [0-10]

10. TICK the one number that describes how, during the past 24 hours, fatigue has interfered with your ENJOYMENT OF LIFE [0-10]

\section{Other questions:}

11. AGE in Years

12. Working Shift i.e. DAY SHIFT or NIGHT SHIFT

13. Relationship Status

14. When I am doing something, I can keep my thoughts on it. Yes No

15. It takes a lot of effort to concentrate on things. Yes__ No

16. Physically I feel I am in a bad condition. Yes

No

17. DID your present sexual activity changed in comparison to 1 year ago? (tick one right option) Increased No change Decreased

18. What makes you feel refreshed and keeps you awake during working hours? MENTION AS MANY AS NEEDED.

19. Tick which of the following recreational substances you use. MENTION AS MANY AS NEEDED.

20. Do you understand the meaning of 'fatigue'? Yes__ No

Visit https://www.ncbi.nlm.nih.gov/pmc/articles/PMC1124000/ 